\title{
Design, In Vitro and In Vivo Characterization of Chitosan-Dextran Sulfate Microparticles for Oral Delivery of Insulin
}

Mikhail A. Pechenkin ${ }^{1 *}$, Nadezhda G. Balabushevich¹, Ivan N. Zorov ${ }^{1}$, Lubov K. Staroseltseva ${ }^{2}$, Elena V. Mikhalchik ${ }^{3}$, Vladimir A. Izumrudov and Natalia I. Larionova ${ }^{1}$

${ }^{1}$ Lomonosov Moscow State University, School of Chemistry; 119991, Moscow, Russia

${ }^{2}$ FGU Endocrinologic Scientific Center; 117036, Dmitry Uljanov str. 11, Moscow, Russia

${ }^{3}$ The Russian State Medical University; 117997, Ostrovitianov str. 1, Moscow, Russia

\begin{abstract}
Microparticles were fabricated by layer-by-layer deposition of chitosan (Ch) and dextran sulfate (DS) on microaggregates formed by human insulin and DS. Consecutive treatment of the negatively charged microaggregates with $\mathrm{Ch}, \mathrm{DS}$, and Ch yielded small (ca. $10 \mu \mathrm{m}$ ) positively charged microparticles with high insulin encapsulation efficiency $(65 \%$ of initial amount of insulin) and loading $(50 \% \mathrm{w} / \mathrm{w})$. Virtually all immobilized protein remained insoluble in the $\mathrm{pH}$ range 1.0-6.0 corresponding to the aggressive media of stomach and upper small intestine, while at $\mathrm{pH} 7.4$, about $90 \%$ of the insulin was released during one-hour incubation. Encapsulated insulin was more resistant to the protease action than native insulin in solution: after 1-h incubation in simulated pancreatic juice only $60 \%$ of encapsulated insulin degraded, while insulin in solution degraded almost completely. Experiments in vivo demonstrated that insulin encapsulated in microparticles preserved biological activity and exerted a prolonged hypoglycemic effect after peroral administration in rabbits and diabetic rats. Bioavailability of the encapsulated insulin administered per os was $11 \%$. The produced microparticles are biocompatible, biodegradable, and mucoadhesive and may be used for the development of oral insulin delivery systems in humans.
\end{abstract}

\section{Introduction}

Insulin is used for treatment of type 1 diabetes mellitus, which is characterized by lack of the internally produced hormone. Traditional injection dosage forms of insulin have a number of serious shortcomings, e.g., permanent violation of skin, variable absorption, and significant intra- and interindividual differences of the pharmacological effect. However, the main problem is the pharmacological profile of traditional insulin preparations that are not able to maintain the plasma concentration of insulin at the physiological level.

Various alternative ways of insulin delivery are intensively developed [1]. Nevertheless, there is only one noninvasive form of insulin (transbuccal Oral-Lyn ${ }^{\mathrm{TM}}$, Generex, USA), which is available in Ecuador and India [2]. Peroral formulation is still considered as the most safe, consistent with natural way of insulin delivery, and of high patient compliance. Insulin adsorbed in intestine transverses liver through portal vein, similar to the normally secreted insulin. Liver, in turn, controls the peripheral insulin concentration [3].

However, bioavailability of orally administered insulin does not exceed 1-2\% [4] due to the protein denaturation in gastric juice with extremely low $\mathrm{pH}$ values, protein cleavage by gastric and intestinal proteolytic enzymes, and poor permeability of intestinal epithelium for the protein molecules [5].

In the last decade, chitosan-polyelectrolyte micro- and nanoparticles with encapsulated insulin were extensively studied as perspective carriers improving bioavailability of the peroral insulin [1]. Cationic polysaccharide chitosan, a deacetylated derivative of chitin, is structurally similar to mucopolysaccharides of human mucosa, e.g., hyaluronic acid, chondroitin, or heparin [6]. Chitosan is a biocompatible, biodegradable, and mucoadhesive polymer with antibacterial activity [7]. Mucoadhesive properties of chitosan can provide intimate and prolonged contact of perorally delivered drug with intestinal epithelium, thus inducing a high drug concentration gradient near the site of adsorption [8]. Chitosan is also able to increase paracellular drug adsorption owing to its ability to open epithelial tight junctions [9]. Chitosan ability to inhibit pepsin can reduce the protein degradation in stomach [10]

Methods of ionotropic gelation [11,12] and consecutive adsorption of polyelectrolytes onto hormone-containing aggregates [13,14] are perspective for preparation of insulin-containing polyelectrolyte micro- and nanoparticles. Both methods are simple and performed in aqueous solutions in the absence of organic solvents. However, low protein content in the particles prepared by ionotropic gelation (no more than 15\%) and their insufficient stability in acidic media make the method of consecutive adsorption more attractive. As it was reported earlier [15], the use of chitosan and dextran sulfate (modified natural polysaccharide carrying on the average 2.3 sulfate groups per one monosaccharide unit) for alternating polyelectrolyte sorption allows fabricating nanostructured microparticles with various proteins. Appropriate $\mathrm{pH}$-sensitivity of the microparticles protects encapsulated proteins from the aggressive stomach medium [13]. Microparticle composition and some release properties were previously published for chitosan-DS microparticles with different proteins, including, porcine insulin and rapid-acting analogues of human insulin $[13,16,17]$. In

*Corresponding author: Mikhail A. Pechenkin, Lomonosov Moscow State University, School of Chemistry; 119991, Moscow, Russia. Tel: +7-495-939-3417 Fax: +7-495-939-5417; E-mail: mapechenkin@gmail.com

Received October 10, 2011; Accepted November 19, 2011; Published Novembe 21,2011

Citation: Pechenkin MA, Balabushevich NG, Zorov IN, Staroseltseva LK Mikhalchik EV, et al. (2011) Design, In Vitro and In Vivo Characterization of Chitosan-Dextran Sulfate Microparticles for Oral Delivery of Insulin. J Bioequiv Availab 3: 244-250. doi:10.4172/jbb.1000094

Copyright: ( 2011 Pechenkin MA, et al. This is an open-access article distributed under the terms of the Creative Commons Attribution License, which permits unrestricted use, distribution, and reproduction in any medium, provided the original author and source are credited. 
this work we present a further study on selection of microparticle preparation condition, more detailed release \& degradation studies, and in vivo evaluation of biological activity after subcutaneous injection and oral administration.

\section{Materials and Methods}

\section{Materials}

Human recombinant insulin zinc salt (Ins) was provided by the Institute of Bioorganic Chemistry, Russia. Dextran sulfate sodium salt, $\mathrm{M}_{\mathrm{w}} 500 \mathrm{kDa}$ (DS); N-benzoyl- $L$-arginine ethyl ester (BAEE), and $\mathrm{N}$-benzoyl- $L$-tyrosine ethyl ester (BTEE) were purchased from Sigma, USA. Chitosan with degree of deacetylation $75-85 \%, \mathrm{M}_{\mathrm{w}} 400 \mathrm{kDa}(\mathrm{Ch})$; a-chymotrypsin, and trypsin were purchased from Fluka, Germany.

\section{Polyelectrolyte microparticle preparation}

Ins-DS microaggregates were prepared by mixing equal volumes of the protein $(20 \mathrm{mg} / \mathrm{ml})$ and dextran sulfate $(5.00-8.75 \mathrm{mg} / \mathrm{ml})$ solution at $\mathrm{pH} 3.0$, as described in [17]. Further $\mathrm{Ch}$ and DS deposition was performed in $0.15 \mathrm{M} \mathrm{NaCl}, 1 \mathrm{mM} \mathrm{HCl}$ at $20^{\circ} \mathrm{C}$ as described in [15]. The prepared microparticles were stored at $4^{\circ} \mathrm{C}$ as suspension; otherwise, they were washed three times with $1 \mathrm{mM} \mathrm{HCl}$ and freeze-dried.

\section{Characterization of microparticles}

Microparticle size and morphology were assessed using conventional light microscope Opton III (Carl Zeiss, Germany), confocal laser scanning microscope Leica TSC SP2 (Leica Microsystems, Germany), and scanning electron microscope Zeiss DSM 40 (Carl Zeiss SMT, Germany, $3 \mathrm{kV}$ ). $\zeta$-Potential measurements were performed in microparticle suspension diluted in $0.01 \mathrm{M} \mathrm{KCl}$ using Malvern Zetasizer II (Malvern Instruments, UK).

\section{Analysis of microparticle composition}

Lyophilized microparticles were preliminary resuspended in $0.1 \mathrm{M} \mathrm{NaOH}$ in order to destroy Ch-DS polyelectrolyte complexes. Ins concentration was measured by the Lowry method [18] and DS concentration by the Dubois method [19]. Ch concentration was determined by the colorimetric assay developed earlier [20], based on the derivatization reaction of the chitosan primary amino groups with o-phthalaldehyde and $\mathrm{N}$-acetyl-l-cysteine. Percentage of the microparticle components was determined as the ratio of the component mass to the mass of the lyophilized microparticles. Encapsulation efficiency was calculated as the ratio of the Ins or DS content determined in the microparticles to the respective amounts of Ins or DS used for the microparticle preparation.

\section{Release of Ins and DS in vitro}

Microparticle suspensions with final protein concentration 0.20 $0.25 \mathrm{mg} / \mathrm{mL}$ were incubated in a shaker-bath with stirring $(100 \mathrm{rpm})$ in universal buffer $\left(0.02 \mathrm{M} \mathrm{H}_{3} \mathrm{PO}_{4}, 0.02 \mathrm{M} \mathrm{CH}_{3} \mathrm{COOH}, 0.02 \mathrm{M} \mathrm{H}_{3} \mathrm{BO}_{3}+\right.$ $0.1 \mathrm{M} \mathrm{NaOH}, \mathrm{pH} 2-8$ ) at room temperature. After 1-h incubation the samples were centrifuged (10000 g, $5 \mathrm{~min}$ ) and concentrations of Ins and DS in the supernatant were measured. The component release was estimated as the ratio of its concentration in supernatant to the initial concentration of the components in suspension.

Kinetics of the protein release was studied as follows. $\mathrm{HCl}$ solution $(\mathrm{pH}$ 1.1) was added to the microparticle suspension up to protein concentration of $0.20-0.25 \mathrm{mg} / \mathrm{mL}$ and the mixture was gently stirred $(100 \mathrm{rpm})$ at room temperature for $2 \mathrm{~h}$. Then the sample was centrifuged (200 g, $2 \mathrm{~min}$ ), supernatant was collected and the equal volume of the universal buffer ( $\mathrm{pH}$ 6.0) was added to the sediment. The resulting suspension of microparticles was incubated with gentle stirring for $2 \mathrm{~h}$ and centrifuged, then the supernatant was replaced with the universal buffer ( $\mathrm{pH} 7.4$ ), and the microparticle suspension was incubated with gentle stirring for $4 \mathrm{~h}$. Every hour after the $\mathrm{HCl}$ solution was first added, an aliquot of the suspension was collected, centrifuged (10000 g, $5 \mathrm{~min}$ ) and the protein content in the supernatant was determined. Protein release from the microparticles was characterized by the ratio of protein concentration in the supernatant to the initial protein concentration in the microparticle suspension.

\section{Evaluation of proteolytic degradation of Ins}

Aliquots of Ins-containing microparticles or Ins solution with protein content $0.5 \mathrm{mg} / \mathrm{mL}$ were incubated at $37^{\circ} \mathrm{C}$ under gentle stirring (100 rpm) either in $0.05 \mathrm{M}$ Tris-buffer ( $\mathrm{pH} 7.1$ ) in the presence of trypsin (700 BAEE U) and chymotrypsin (4 BTEE U) for $1 \mathrm{~h} \mathrm{[21]} \mathrm{or}$ in $0.05 \mathrm{M}$ Tris-buffer ( $\mathrm{pH} 7.8$ ) in the presence of trypsin (140 BAEE $\mathrm{U})$ for $6 \mathrm{~h}$ [22]. Trypsin and chymotrypsin activities of the commercial preparations (9000 BAEE U/mg and $39 \mathrm{BTEE} \mathrm{U/mg} \mathrm{respectively)}$ were measured as described in [23]. Proteolysis was stopped by the addition of trifluoroacetic acid to final concentration of $0.1 \%$, samples were centrifuged (10000 g, $5 \mathrm{~min}$ ), and the content of the remaining undegraded Ins in supernatants was measured by high-performance liquid chromatography (Agilent 1100 Series, Hewlett Packard, USA). A reversed-phase $\mathrm{C} 18$ column and gradient elution with a mobile phase composed of $0.1 \%$ acetonitrile and $0.1 \%$ aqueous trifluoroacetic acid solutions at a flow rate of $1 \mathrm{~mL} / \mathrm{min}$ was used. Protein was detected by UV spectroscopy at $215 \mathrm{~nm}$. The gradient changed from 20:80 (acetonitrile solution: water solution, v/v) to $50: 50(\mathrm{v} / \mathrm{v})$ within $5 \mathrm{~min}$; for further $10 \mathrm{~min}$ isocratic elution at 50:50 (v/v) was performed. Ins degradation was calculated as a relative difference (\%) of the Ins peak areas before and after proteolysis.

\section{In vivo studies of biological activity of microparticles in rabbits}

Chinchilla male rabbits $(2.5-3.5 \mathrm{~kg})$ were kept on standard diet in the vivarium of the university in an air-conditioned animal room $\left(22 \pm 2^{\circ} \mathrm{C}\right)$ under a $12 \mathrm{~h}$ light/dark cycle. The animals were fasted $3 \mathrm{~h}$ before and $3 \mathrm{~h}$ during experiments and had free access to water. Ins preparations were injected subcutaneously in a volume of $1 \mathrm{~mL}$ containing a dose of $4 \mathrm{IU} / \mathrm{kg}$. During peroral administration the same dose of $4 \mathrm{IU} / \mathrm{kg}$ was introduced in $3 \mathrm{~mL}$ of microparticle suspension by the base of tongue and then washed by additional $5 \mathrm{~mL}$ of water. Control group did not get any Ins-containing preparations. Each group numbered 5-6 animals. Blood sampling was performed from boundary vein of the rabbit's right ear. Glucose level in blood samples was evaluated by OneTouch ${ }^{\otimes}$ II device using test stripes OneTouch (LifeScan, USA).

\section{In vivo studies of biological activity of microparticles in diabetic rats}

Male Wistar rats (250-350 g) were housed in cages in the vivarium of the university in an air-conditioned animal room $\left(22 \pm 2^{\circ} \mathrm{C}\right)$ under a $12 \mathrm{~h}$ light/dark cycle fed laboratory animal standard diet and provided with tap water. Rats were rendered diabetic by a single intraperitoneal injection of $50 \mathrm{mg} / \mathrm{kg}$ streptozotocin $(26.6 \mathrm{mg} / \mathrm{mL}$ in citrate solution, 
Citation: Pechenkin MA, Balabushevich NG, Zorov IN, Staroseltseva LK, Mikhalchik EV, et al. (2011) Design, In Vitro and In Vivo Characterization of Chitosan-Dextran Sulfate Microparticles for Oral Delivery of Insulin. J Bioequiv Availab 3: 244-250. doi:10.4172/jbb.1000094

$\mathrm{pH}$ 4.5). Two weeks later, rats with fasting blood glucose level above $13 \mathrm{mM}$ were randomly grouped into four: control, treated with 10 $\mathrm{IU} / \mathrm{kg}$ or $25 \mathrm{IU} / \mathrm{kg}$ insulin microparticles and reference groups, each numbering 5-7 animals. The rats were fasted $12 \mathrm{~h}$ before and $24 \mathrm{~h}$ after insulin administration and had free access to water.

In the treated groups and in the control group the samples $(0.5$ $\mathrm{mL})$, containing microparticle suspension or equivalent volume of 0.15 $\mathrm{M} \mathrm{NaCl}, 1 \mathrm{mM} \mathrm{HCl}$, respectively, were administered by oral gavage. In the reference group insulin was administered by subcutaneous injection $(2.5 \mathrm{IU} / \mathrm{kg})$. In each group blood samples $(0.05 \mathrm{~mL})$ were collected from the tail vein. Blood glucose level was determined using the Glukoza-agat Kit, (Agat-med, Russia; range 2-20 mM) and expressed as a percent of the baseline plasma glucose level.

Plasma glucose levels were plotted against time to evaluate the cumulative hypoglycemic effect over time after the insulin administration, quantified by the area above the curve, determined by the trapezoidal method. Pharmacological availability (PA) of encapsulated insulin administered perorally was determined as the relative measure of the cumulative reduction in glucose blood levels as compared to $100 \%$ availability of the reference subcutaneous insulin injection of $2.5 \mathrm{IU} / \mathrm{kg}$ insulin.

Approvals for the in vivo study protocols were gained from the Animal Ethics Committee of the Russian Medical State University.

\section{Results and Discussion}

\section{Preparation of polyelectrolyte microparticles}

Insulin-containing microparticles were prepared by consecutive adsorption of oppositely charged DS and Ch onto microaggregates of insoluble (Ins-DS) polyelectrolyte complex in $0.15 \mathrm{M} \mathrm{NaCl}, \mathrm{pH}$ 3.0 (Figure 1). The choice of polyelectrolytes (Ch, $400 \mathrm{kDa}$ and $\mathrm{DS}$, $500 \mathrm{kDa}$ ) for the microparticle preparation has been substantiated in previous studies $[13,16]$.

The aim of the first step was to obtain Ins-DS aggregates (particle size of $1-10 \mu \mathrm{m}$ ) with high protein content and a negative surface charge that would provide further electrostatic interaction of the microaggregates with positively charged chitosan (Figure 1). Micron size of the aggregates is required for effective centrifugation and resuspension during microparticle preparation.

The presence of 2.3 sulfate groups per one glucosyl residue in DS provides a high density of negative charge (mass/charge ratio is

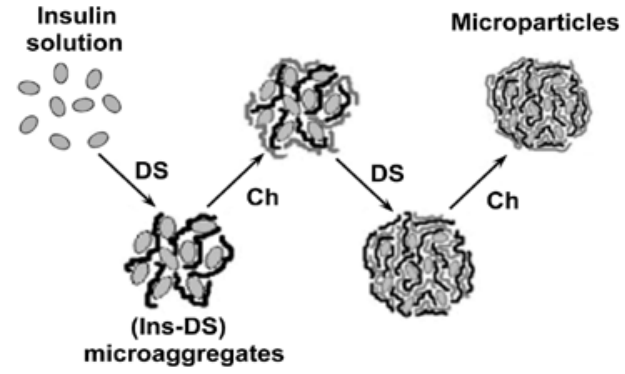

Figure 1: Scheme of the microparticles preparation by consecutive adsorption of the oppositely charged polyelectrolytes onto Ins-DS microaggregates.

\begin{tabular}{|c|c|c|c|}
\hline $\begin{array}{c}\text { Ins:DS ratio during } \\
\text { microaggregate preparation, } \\
(w / w)\end{array}$ & $\begin{array}{c}\text { Ins encapsulation } \\
\text { efficiency, } \%\end{array}$ & $\zeta$-potential, mV & $\begin{array}{c}\text { Mean size, } \\
\mu \mathrm{m}\end{array}$ \\
\hline $7: 1$ & $38 \pm 1$ & $19 \pm 2$ & $3 \pm 1$ \\
\hline $5: 1$ & $94 \pm 2$ & $7 \pm 1$ & $3 \pm 2$ \\
\hline $4: 1$ & $98 \pm 3$ & $-29 \pm 3$ & $9 \pm 3$ \\
\hline
\end{tabular}

Table 1: Characterization of microaggregates of Ins-DS complexes.

\begin{tabular}{|c|c|c|c|c|c|c|}
\hline \multirow[t]{2}{*}{ Microparticles } & \multirow{2}{*}{$\begin{array}{c}\text { No of } \\
\text { adsorption } \\
\text { steps (s) }\end{array}$} & \multirow{2}{*}{$\begin{array}{c}\text { Ins } \\
\text { encapsulation } \\
\text { efficiency, } \%\end{array}$} & \multicolumn{3}{|c|}{$\begin{array}{l}\text { Content, } \\
\text { w/w \%* }\end{array}$} & \multirow{2}{*}{$\begin{array}{c}\text { Mean } \\
\text { size, } \mu \mathrm{m}\end{array}$} \\
\hline & & & Ins & DS & $\mathrm{Ch}$ & \\
\hline (Ins-DS) & 1 & $97 \pm 3$ & $81 \pm 4$ & $17 \pm 5$ & - & $9 \pm 2$ \\
\hline (Ins-DS)-Ch & 2 & $67 \pm 2$ & $63 \pm 3$ & $21 \pm 3$ & $19 \pm 2$ & $10 \pm 2$ \\
\hline (Ins-DS)-Ch-DS & 3 & $65 \pm 3$ & $57 \pm 2$ & $28 \pm 5$ & $15 \pm 2$ & $12 \pm 2$ \\
\hline (Ins-DS)-Ch-DS-Ch & 4 & $65 \pm 2$ & $57 \pm 4$ & $26 \pm 3$ & $17 \pm 2$ & $9 \pm 2$ \\
\hline
\end{tabular}

${ }^{*}$ Ratio of the component to microparticle weight

Table 2: Characterization of insulin-containing polyelectrolyte microparticles.

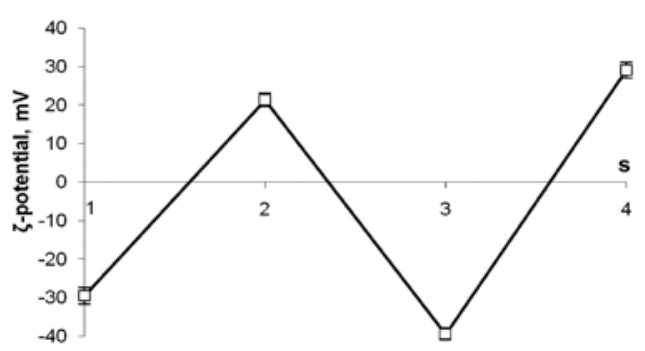

Figure 2: $\zeta$-Potential of the microparticles plotted as a function of the polyelectrolyte adsorption stage (s). 1 - Ins-DS microaggregates; 2 - Ch adsorbtion; 3 - DS adsorbtion; 4 - another Ch adsorbtion.

$183 \mathrm{~m} / \mathrm{z}$ ), which is largely unchanged at all $\mathrm{pH}$ values. The human recombinant insulin zinc salt mainly persists in solution as a hexamer [24]. Theoretical calculations using the modified Tanford-Kirkwood model $[25,26]$ revealed that insulin hexamer $(\mathrm{pI}=5.35)$ at $\mathrm{pH} 3.0$ is a sphere with a radius of $25 \AA ⿱ ㇒ ⿸ ⿻ 日 丿 乚 厶$ and a charge of +26 , which corresponds to a mass/charge ratio of $1340 \mathrm{~m} / \mathrm{z}$. These calculations were confirmed by the results of turbidimetric titration of insulin solution by DS solution with Ins:DS weight ratios from 14:1 to 4:1. A maximum on the titration curves at the component ratio 7:1 indicated a complete neutralization of the protein. This ratio corresponds to a charge of hexameric Ins of +24 ( +4 per monomer), which is close to the theoretically calculated value of +26 . Assuming that not all Ins molecule charges are exposed, $\zeta$-potential measurements should show neutralization at smaller ratio, that is generally consistent with the data shown in (Table 1). A zero $\zeta$-potential corresponded to weight ratio ca. 5:1 and during further titration acquired a negative charge. In the following experiments, negatively charged Ins-DS aggregates prepared at the ratio of 4:1 were used. Under these conditions the efficiency of the protein and DS incorporation was the highest with mean size of microaggregates about $10 \mu \mathrm{m}$ (Table 1). On the average, one molecule of DS bound to 290 molecules of Ins.

At the second step negatively charged aggregates were treated with chitosan solution and then a sequential adsorption of DS and $\mathrm{Ch}$ was carried out as described above. The first $\mathrm{Ch}$ addition led to a significant loss of the protein (Table 2). Apparently, charged cationic 
Citation: Pechenkin MA, Balabushevich NG, Zorov IN, Staroseltseva LK, Mikhalchik EV, et al. (2011) Design, In Vitro and In Vivo Characterization of Chitosan-Dextran Sulfate Microparticles for Oral Delivery of Insulin. J Bioequiv Availab 3: 244-250. doi:10.4172/jbb. 1000094

polysaccharide competitively replaces Ins from the microaggregates forming more stable polyelectrolyte complex with anionic DS. The following alternating treatment had no significant effect on the protein encapsulation efficiency; microparticle size was about $10 \mu \mathrm{m}$ (Table 2). The more sorption stages were carried out the higher was the DS and Ch percentage. Microparticles with number of stages of the polyelectrolyte adsorption (s) from 1 to 4 were prepared. Ins:DS:Ch ratio in final particles $(s=4)$ was about 2.5:1:1 [11].

The sign of $\zeta$-potential depended on the polyelectrolyte of the outmost layer (Figure 2). The microparticles possessed positive or negative surface charge after the adsorption of Ch or DS, respectively. The value of $\zeta$-potential not only allowed estimation of the fullness of the polyelectrolytes sorption but also made it possible to predict mucoadhesive properties of the microparticles. It is well-documented that mucus layer of intestine is negatively charged due to terminal
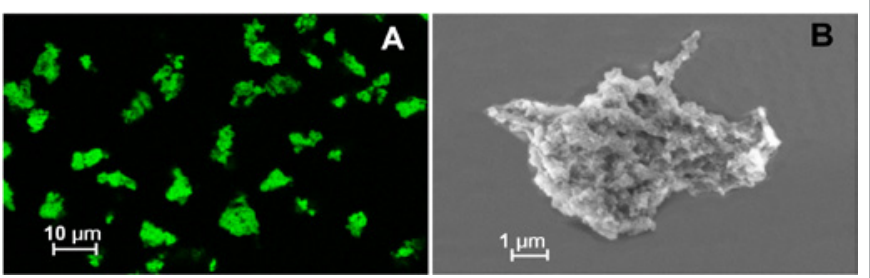

Figure 3: Confocal laser scanning $(\boldsymbol{A})$ and scanning electron microphotographs $(B)$ of insulin-containing microparticles $(s=4)$.
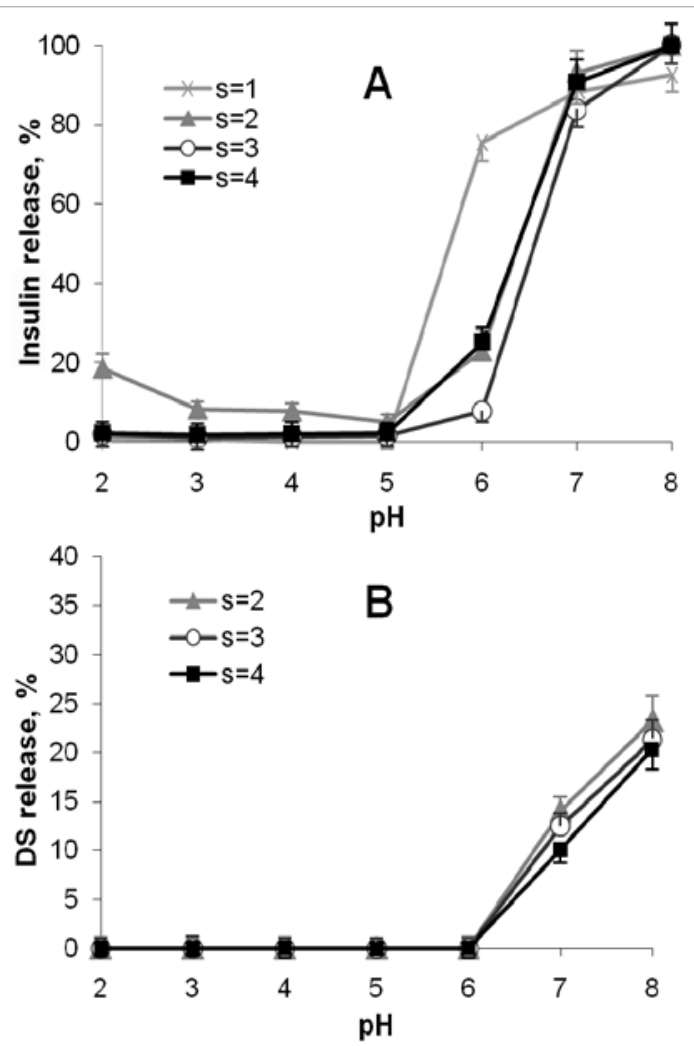

Figure 4: pH-Sensitive release of Ins $(\boldsymbol{A})$ and DS $(\boldsymbol{B})$ from microparticles prepared by different number of stages of the polyelectrolyte adsorption (s). Incubation time, $1 \mathrm{~h}$. Average of 3 experiments, mean \pm SD. sialic acid residues of mucopolysaccharides [27]. That is why positive charge of the chitosan-coated microparticles could improve their mucoadhesive properties.

Microscopic studies indicated that microparticles retained the shape of the initial microaggregates, i.e., irregular-shaped particles with size range from 3 to $15 \mu \mathrm{m}$ (Figure 3).

\section{pH-Sensitivity of the micro particles}

The main goal of the research was to develop an Ins preparation that would retain its activity and efficiency when administered orally. In other words, the protein should be protected from pepsin in strongly acidic stomach medium and be released and absorbed in the small intestine. pH-Sensitivity of the microparticles (Figure 4) seems to be appropriate. According to the results of analysis of the protein content in supernatants (Figure 4A), microparticles $(s=2)$ prepared by sorption of chitosan onto Ins-DS aggregates released Ins in strongly acidic media. This can be explained by positive $\zeta$-potential of microparticles after chitosan sorption and competitive replacement of DS-bound Ins by the added Ch. In acidic media, the charge of Ins is increased forming the excess of positive charge on microparticles that results in displacement of a part of Ins molecules from the complex. As far as the polysaccharides in Ch-DS complex are more tightly bound than the protein in Ins-DS complex, some of the Ins molecules are released. Further polyelectrolyte coating of the microparticles prevents insulin from leakage in acidic medium. It is important that in the $\mathrm{pH}$ range of $6-7$, a cooperative destruction of the microparticles with almost complete release of Ins occurred. This is clearly caused by Ins molecule recharging $(\mathrm{pI}=5.35)$ and competitive displacement of the negatively charged protein from the insoluble particles. In the same $\mathrm{pH}$ range, deprotonation of $\mathrm{Ch}(\mathrm{pKa}=6.4)$ takes place along with the Ins recharging. This should facilitate the formation of soluble polyelectrolyte complexes of Ch-DS [28], since solubilizing ability of highly charged DS increases as the charge of the cationic polysaccharide decreases. This assumption is supported by the analysis of anionic polysaccharide concentration in supernatants (Figure 4B). All DS chains remained in microparticles at $\mathrm{pH}$ up to $6.0(\mathrm{~s}=2-4)$ and then released into solution almost linearly. Note that DS molecules released much less effectively than the protein did (Figure 4A). Thus, only a quarter of the original content of the polysaccharide in the microparticles was found in the supernatant at $\mathrm{pH}$ 8.0. This value remained constant for all the microparticles $(s=2-4)$. A complete release of DS was likely prevented by formation of hydrogen bonds with deprotonated amino groups of Ch that stabilized the insoluble complex.

It should be noted that Ins was almost completely removed from the microparticles at pH 7.0 (Figure 4A), whereas only $10 \%$ of DS was released (Figure 4B). These results are in agreement with a previous report confirming that Ins is released from the microparticles as hexamer, which does not associate with the polyelectrolytes (according to gel chromatography) [29].

\section{Kinetics of Ins release from microparticles}

The kinetics of Ins release was studied under the conditions simulating the change of luminal $\mathrm{pH}$ of the gastrointestinal tract ( $\mathrm{s}=4$, Figure 5). For the first $2 \mathrm{~h}$ microparticles were incubated at $\mathrm{pH} 1.1$ imitating acidic stomach medium; then for $2 \mathrm{~h}$, at $\mathrm{pH} 6.0$ corresponding to the medium acidity of duodenum, and after that, for $4 \mathrm{~h}$, at $\mathrm{pH} 7.4$ corresponding to the lower sections of small intestine. Release curves confirmed that Ins was retained in the microparticles at $\mathrm{pH}$ 1.1. At $\mathrm{pH}$ 
6.0 a slight release of the protein (no more than $2 \%$ ) was observed. This differs from the data shown in (Figure 4A), when almost $30 \%$ of Ins was released after $1-\mathrm{h}$ incubation at $\mathrm{pH}=6.0$. This discrepancy is likely associated with stabilizing effect of the incubation of microparticles at low $\mathrm{pH}$ prior to the application of $\mathrm{pH}=6.0$ : in the acidic medium $\mathrm{Ch}$ and Ins attain more positive charges stabilizing their complex with DS. This effect weakens at $\mathrm{pH} 7.4$, and about $85 \%$ of Ins releases within the first hour of incubation at $\mathrm{pH}$ 7.4. The rest of Ins was released from the microparticles within the next $3 \mathrm{~h}$ of incubation.

Thus, polyelectrolyte microparticles prepared by four cycles of polyelectrolyte sorption exhibit a high efficiency of protein encapsulation (about 65\%), small size (about $10 \mu \mathrm{m}$ ), stability at low $\mathrm{pH}$ (from 2 to 5) corresponding to the acidity of stomach medium, and release of Ins at $\mathrm{pH}$ over 6 corresponding to $\mathrm{pH}$ of intestine medium. The use of cationic polysaccharide $\mathrm{Ch}$ at the last cycles of sorption provides positive $\zeta$-potential of the microparticles and should enhance their adhesion to intestinal epithelium. All these features make the particle a perspective vehicle for peroral Ins delivery.

\section{Protease resistance of microencapsulated insulin}

Conditions recommended by A. Bernkop-Schnürch were chosen to study Ins proteolysis in small intestine. These conditions imitate two different divisions of human intestine: pancreatic juice $(\mathrm{pH} 7.1)$ [21] and luminal juice of the lower parts of the small intestine ( $\mathrm{pH} 7.8$ ) [22] (Table 3). Ins encapsulation into polyelectrolyte microparticles reduced but did not completely prevent proteolytic cleavage of Ins. In pancreatic juice the protective effect was the most significant: $40 \%$ of Ins avoided proteolysis in microparticles, whereas almost all native Ins was hydrolyzed after $1 \mathrm{~h}$ incubation. In simulated lower parts of the small intestine the amount of undegraded Ins in microparticles was 2 times more than that of native Ins in solution. The protective properties

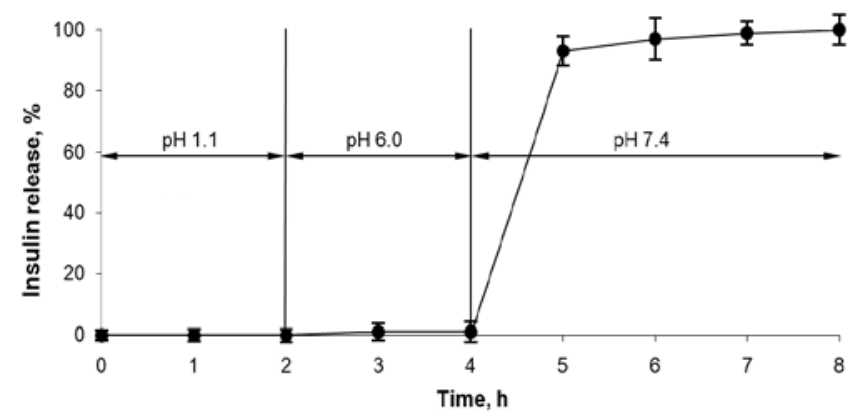

Figure 5: Kinetics of the Ins release from microparticles $(s=4)$ under the conditions simulating human gastrointestinal media. Average of 3 experiments, mean $\pm \mathrm{SD}$.

\begin{tabular}{|c|c|c|c|c|}
\hline \multirow{2}{*}{ Medium } & Conditions & $\begin{array}{l}\text { Incubation } \\
\text { duration, } \mathrm{h}\end{array}$ & $\begin{array}{c}\text { Degradation, \% } \\
\text { Insulin } \\
\text { solution }\end{array}$ & $\begin{array}{c}\text { Microparticles } \\
\text { (s=4) with insulin }\end{array}$ \\
\hline $\begin{array}{c}\text { Pancreatic } \\
\text { juice }\end{array}$ & $\begin{array}{c}\text { Trypsin, 700 BAEE U/ } \\
\text { ml; chymotrypsin, } \\
\text { BTEE U/ml, pH 7.1 } \\
{[21]}\end{array}$ & 1 & $99 \pm 1$ & $60 \pm 1$ \\
\hline Ileum medium & $\begin{array}{c}\text { Trypsin, 140 BAEE U/ } \\
\text { ml, pH 7.8 [22] }\end{array}$ & 6 & $76 \pm 2$ & $53 \pm 1$ \\
\hline
\end{tabular}

Table 3: Ins proteolysis in gastrointestinal media.

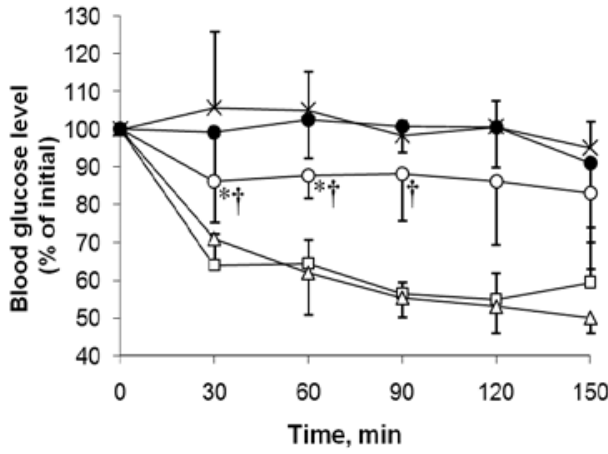

Figure 6: Hypoglycemic activity of Ins-containing microparticles after subcutaneous and peroral administrations to healthy rabbits $(4 \mathrm{lU} / \mathrm{kg}) .(\times)-0.15 \mathrm{M}$ $\mathrm{NaCl}$ solution, $\mathrm{pH} 3.0$; $(\square)$ - Ins solution subcutaneously; $(\Delta)$ - microparticles subcutaneously; $(\bullet)$ - microparticles perorally to animals with initial glucose level less than $5.5 \mathrm{mM}$; ( ) - microparticles perorally to animals with initial glucose level over $5.5 \mathrm{mM}$. * Shows statistically significant difference between animals treated with microparticle (at initial glucose level more than $5.5 \mathrm{mM}$ and control group (untreated), $\uparrow$ shows statistically significant difference between animals with initial glucose level over $5.5 \mathrm{mM}$ and less than $5.5 \mathrm{mM}(p<0.05)$

of the microparticles can derive from formation of DS-protease complex, $\mathrm{Ca}^{2+}$-binding ability of DS decreasing enzyme activity [17], and from the steric effect of polyelectrolyte network hindering the access of proteases to the encapsulated Ins. Another possibility is sorption of proteases on the microparticles remaining after Ins release; such microparticles acquire negative charge $(-39 \mathrm{mV})$ and may bind proteases thus reducing their concentration in the medium.

\section{Hypoglycemic activity of microencapsulated Ins in vivo}

Healthy rabbits: Biological activity of Ins-containing microparticles $(s=4)$ was evaluated in healthy rabbits. After a subcutaneous injection of soluble or encapsulated Ins at a dose of $4 \mathrm{IU} / \mathrm{kg}$ blood glucose level decreased by $40 \%$ within one hour (Figure 6).

For in vivo testing of peroral insulin preparations, diabetic rats [12,30], mice [31] and, less frequently, rabbits [32] are usually used. However, rabbits seem to be an appropriate object for studies of peroral preparations as gastrointestinal tract of rabbits bares similarity to the human's one by such parameters as relative intestine surface area, $\mathrm{pH}$ values of intestine divisions, microflora, etc. [33]. Because of low bioavailability of oral preparations of Ins, high doses of Ins - from 20 [30] to $100 \mathrm{IU} / \mathrm{kg}$ [12] - are usually used. We studied a hypoglycemic activity of Ins-containing microparticles after peroral administration of a low Ins dose of $4 \mathrm{IU} / \mathrm{kg}$, similar to subcutaneous injections. Animals were divided into two groups depending on their initial blood glucose level (Figure 6). In the first group with normal initial glucose concentration, no hypoglycemic activity was observed. In the other group with high initial blood glucose level $(>5.5 \mathrm{mM})$, hypoglycemic effect (by up to 17\%) was manifested for $150 \mathrm{~min}$. These findings correspond well to the previously reported observations [34] that revealed a hypoglycemic effect of peroral insulin preparation only in diabetic animals or in animals with elevated initial blood glucose level.

Diabetic rats: The next step was to study hypoglycemic activity and to evaluate pharmacological availability of peroral microencapsulated insulin using streptozotocin-induced rat model of diabetes. In this study the doses were lowered down to 10 and $25 \mathrm{IU} / \mathrm{kg}$ since an efficiency at 


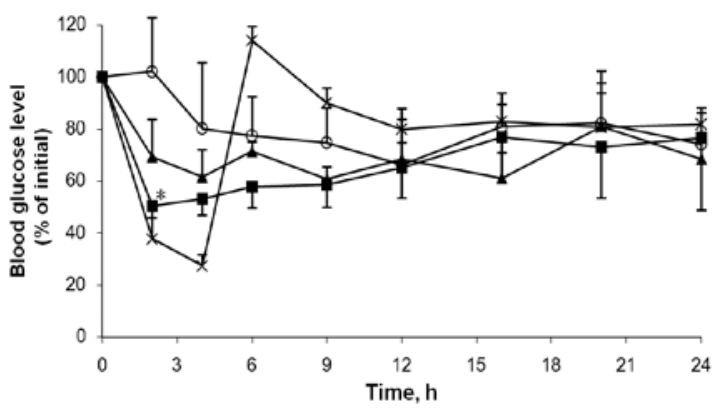

Figure 7: Plasma glucose levels in diabetic rats after oral administration of insulin-loaded microparticles $10(\boldsymbol{\Delta})$ and $25(\mathbf{m}) \mathrm{IU} / \mathrm{kg}$ and $0.15 \mathrm{M} \mathrm{NaCl}$ solution, $\mathrm{pH} 3.0$ (०), compared to $2.5 \mathrm{IU} / \mathrm{kg}$ delivered subcutaneously $(\times) .{ }^{*}$ Shows statistically significant difference between animals treated with orally administered microparticles $25 \mathrm{IU} / \mathrm{kg}$ and control group (untreated) $(p<0.05)$.

50 and $100 \mathrm{IU} / \mathrm{kg}$ was already confirmed for dextran sulfate-chitosan particles prepared by ionotropic gelation method [35]. At the dose of $25 \mathrm{IU} / \mathrm{kg}$, blood glucose level decreased to $50 \%$ and then did not change for $10 \mathrm{~h}$ (Figure 7).

In order to estimate oral bioavailability of insulin-loaded microparticles, insulin solution was subcutaneously administered to rats at a dose of $2.5 \mathrm{IU} / \mathrm{kg}$. Pharmacological availability of perorally administered microencapsulated insulin was estimated to be near $10 \%$ as compared to subcutaneous injection. This value significantly exceeds the bioavailability of dextran sulfate-chitosan nanoparticles with low protein loading capacity $(5.6 \%,[35])$ and allows one to reach similar hypoglycemic effect using almost 2 times lower doses. This advantage of the studied microparticles may be attributed to a much higher loading capacity (57\% against $2.3 \%$ in [35]) and the presence of chitosan on the microparticle surface providing positive $\zeta$-potential and mucoadhesive properties [17] that are absent in the dextran sulfate-chitosan nanoparticles. Positive $\zeta$-potential enhances microparticle attachment to negatively charged intestinal epithelium, while mucoadhesiveness of the microparticles provides a prolonged intimate contact of insulin carrier to mucus layer, providing insulin release in the proximity to the site of adsorption and high concentration gradient due to high microparticle loading capacity.

Shorter duration of hypoglycemic action (10 h against $24 \mathrm{~h}$ for nanoparticles) may be explained by the particle size. Microparticles, unlike nanoparticles, are poorly captured by the M cells of the Peyer's patches and insulin can reach the bloodstream via a paracellular pathway due to the chitosan ability to open epithelial tight junctions [36].

\section{Conclusions}

Microparticles containing human recombinant insulin were prepared by layer-by-layer adsorption of oppositely charged biocompatible polysaccharidesDS and Ch onto Ins-DSmicroaggregates. Positively charged microparticles obtained after four-step $(s=4)$ sorption, featured a relatively high Ins loading and stability in a wide $\mathrm{pH}$ range, from strongly acidic media imitating stomach to weakly acidic media. At neutral $\mathrm{pH}$ values imitating small intestine lumen, Ins started to be released, and at $\mathrm{pH} 8.0$ practically all Ins molecules were released within one hour. The ability of the microparticles to protect Ins against cleavage by intestinal proteases has been established. All these properties, together with microparticle mucoadhesivity due to the $\mathrm{Ch}$ coating, notably improve Ins bioavailability upon oral administration of microparticles.

Preservation of Ins biological activity during encapsulation into polyelectrolyte microparticles was confirmed. Hypoglycemic activity of Ins-loaded microparticles was revealed at a dose of $4 \mathrm{IU} / \mathrm{kg}$ after peroral administration to healthy rabbits with elevated blood glucose level. A prolonged (up to $10 \mathrm{~h}$ ) and dose-dependent hypoglycemic effect was ascertained after peroral administration of polyelectrolyte insulincontaining microparticles to diabetic rats at doses of 10 and $25 \mathrm{IU} / \mathrm{kg}$. Bioavailability of perorally administered microencapsulated insulin was estimated to be $10.7 \%$ as compared to subcutaneous injection.

\section{Acknowledgements}

The authors are grateful to E.D. Shibanova and D.I. Bairamishvili (ShemyakinOvchinnikov Institute of Bioorganic Chemistry, Russian Academy of Sciences Moscow) for kindly provided human recombinant insulin and to Prof. A.V. Kabanov (Pharmaceutical Faculty, Nebraska Stare University, USA), for consulting

This work was partially supported by the Russian Foundation for Basic Research (project No. 09-04-12149a) and by contract No. 11.G34.31.0004 of the Ministry of Science and Education of the Russian Federation.

\section{References}

1. Zubaerova DK, Larionova NI (2008) Noninvasive Insulin Delivery Systems Biomed Khim 2: 346-355

2. Nash G (2008) http://www.generex.com/press_release_desc.php?id=65.

3. Haverstick DM, Dickemper D, Gold AH (1979) Cycloheximide inhibition of insulin control of liver glycogen synthase $b$ into a conversion. Biochem Biophys Res Commun 87: 177-183.

4. Carino GP, Mathiowitz E (1999) Oral insulin delivery. Adv Drug Deliv Rev 35 249-257.

5. Hamman JH, Enslin GM, Kotzé AF (2005) Oral delivery of peptide drugs: barriers and developments. BioDrugs 1: 165-177.

6. Lehr CM, Bouwstra JA, Schacht EH, Junginger HE (1992) In vitro evaluation of mucoadhesive properties of chitosan and some other natural polymers. Int $J$ Pharm 78: 43-48.

7. Prabaharan M, Mano JF (2005) Chitosan-based particles as controlled drug delivery systems. Drug Deliv 12: 41-57.

8. Ziv E, Bendayan M (2000) Intestinal absorption of peptides through the enterocytes. Microsc Res Tech 49: 346-352.

9. Dodane V, Amin Khan M, Merwin JR (1999) Effect of chitosan on epithelial permeability and structure. Int J Pharm 182: 21-32.

10. Paul W, Sharma CP (2000) Chitosan, a drug carrier for the $21^{\text {st }}$ century: a review. S.T.P. Pharma Sci 10: 5-22

11. Sarmento B, Ribeiro A, Veiga F, Ferreira D (2006) Development and characterization of new insulin containing polysaccharide nanoparticles. Colloids Surf B: Biointerfaces 53: 193-202.

12. Pan Y, Li Y, Zhao H, Zheng J, Xu H, et al. (2002) Bioadhesive polysaccharide in protein delivery system: chitosan nanoparticles improve the intestinal absorption of insulin in vivo. Int J Pharm 249: 139-147.

13. Balabushevich NG, Izumrudov VA, Zorov IN, Larionova NI (2010) Development of chitosan-containing polyelectrolyte microparticles for peroral protein delivery. Biopharm J 2: 35-41. [in Russian with English abstract].

14. Fan YF, Wang YN, Fan YG, Ma JB (2006) Preparation of insulin nanoparticles and their encapsulation with biodegradable polyelectrolytes via the layer-bylayer adsorption. Int J Pharm 324: 158-167.

15. Balabushevich NG, Lebedeva OV, Vinogradova OI, Larionova NI (2006) Polyelectrolyte assembling for protein microencapsulation. J Drug Del Sci Tech 16: $315-319$ 
Citation: Pechenkin MA, Balabushevich NG, Zorov IN, Staroseltseva LK, Mikhalchik EV, et al. (2011) Design, In Vitro and In Vivo Characterization of Chitosan-Dextran Sulfate Microparticles for Oral Delivery of Insulin. J Bioequiv Availab 3: 244-250. doi:10.4172/jbb.1000094

16. Balabushevich NG, Vikhoreva GA, Mikhal'chik EV, Larionova NI (2010) Fabrication and properties of $\mathrm{pH}$-sensitive nanostructured polyelectrolyte microparticles loaded with insulin. Moscow University Chemistry Bulletin 65: 148-153.

17. Balabushevich NG, Pechenkin MA, Zorov IN, Shibanova ED, Larionova NI (2011) Mucoadhesive polyelectrolyte microparticles containing recombinant human insulin and its analogs aspart and lispro. Biochemistry (Moscow) 76: 327-331.

18. Lowry OH, Rosebrough NJ, Farr AL, Randall RJ (1951) Protein measurement with the Folin phenol reagent. J Biol Chem 193: 265-275.

19. Dubois M, Gilse A, Hamilton SK, Robers PA, Smith F (1956) Colorimetric method for determination of sugars and related substances. Anal Chem 28: 350-356.

20. Larionova NI, Zubaerova DK, Guranda DT, Pechyonkin MA, Balabushevich NG (2009) Colorimetric assay of chitosan in presence of proteins and polyelectrolytes by using o-phthalaldehyde. Carb Polym 75: 724-727.

21. Marschütz MK, Bernkop-Schnürch A (2000) Oral peptide drug delivery: polymer-inhibitor conjugates protecting insulin from enzymatic degradation in vitro. Biomaterials 21: 1499-1507.

22. Bernkop-Schnürch A (2005) Mucoadhesive systems in oral drug delivery. Drug Discov Today: Technologies 2: 83-87.

23. Schwert GW, Takenaka Y (1955) A spectrophotometric determination of trypsin and chymotrypsin. Biochim Biophys Acta 16: 570-575.

24. Blundell T, Dodson G, Hodgkin D, Mercola D (1972) Insulin: the structure in the crystal and its reflection in chemistry and biology. Adv Protein Chem 26: 279-402.

25. Tanford C, Kirkwood JG (1957) Theory of protein titration curves. I. General equations for impenetrable spheres. J Am Chem Soc 79: 5333-5339.

26. Tanford C, Roxby R (1972) Interpretation of protein titration curves. Application to lysozyme. Biochemistry 11: 2192-2198.

27. Peppas NA, Sahlin JJ (1996) Hydrogels as mucoadhesive and bioadhesive materials: a review. Biomaterials 17: 1553-1561.

28. Izumrudov VA, Volkova IF, Gorshkova MY (2010) Chitosan-based Polyelectrolyte Complexes Soluble in Enzyme-friendly pH Range Macromol Chem Phys 211: 453-460.

29. Balabushevich NG, Larionova NI (2004) Fabrication and Characterization of Polyelectrolyte Microparticles with Protein. Biochemistry Moscow 69: 757-762.

30. Cui F, Zhang L, Zheng J, Kawashima Y (2004) A study of insulin-chitosan complex nanoparticles used for oral administration. J Drug Del Sci Tech 14: 435-439.

31. Marschütz MK, Calceti $P$, Bernkop-Schnürch A (2000) Design and in vivo evaluation of an oral delivery system for insulin. Pharm Res 17: 1468-1474.

32. Valuev IL, Sytov GA, Valuev LI, Valueva TA, Ul'ianova MV, et al. (2001) Inhibitors of proteolytic enzymes in the therapy of diabetes. Vopr Med Khim 47: 132-137. [in Russian with English abstract]

33. Kararli TT (1995) Comparison of the gastrointestinal anatomy, physiology, and biochemistry of humans and commonly used laboratory animals. Biopharm Drug Dispos 16: 351-380.

34. Damgé C, Michel C, Aprahamian M, Couvreur P, Devissaguet JP (1990) Nanocapsules as carriers for oral peptide delivery. J Control Rel 13: 233-239.

35. Sarmento B, Ribeiro A, Veiga F, Ferreira D, Neufeld R (2007) Oral bioavailability of insulin contained in polysaccharide nanoparticles. Biomacromolecules 8: 3054-3060.

36. Ma Z, Lim TM, Lim LY (2005) Pharmacological activity of peroral chitosaninsulin nanoparticles in diabetic rats. Int J Pharm 293: 271-280. 